\title{
Pharmacists' perceptions of the impact of care they provide
}

\author{
Peter LOEWEN, Faye MERRETT, Jane DE LEMOS. \\ Received (first version): 12-Sep-2009 Accepted: 7-Apr-2010
}

\begin{abstract}
Limitations on health care resources necessitate careful focus on activities that lead to the greatest improvement in patient outcomes. Despite the importance of aligning pharmacists' time with activities deriving the most impact, there is a paucity of literature on the correlations between pharmacists' perceptions of the impact of their activities, how they actually spend their time and how these align with published evidence of impacts on patient outcomes.

Objective: To reveal hospital pharmacists' perceptions of the impacts of their clinical activities and to characterize the correlation between the activities performed and both their perceptions of and the published evidence for their impacts on patient care.

Methods: Observational qualitative interviews and quantitative questionnaires were conducted with each participant $(\mathrm{N}=21)$ to characterize their work day and determine their perceptions of the impact of their activities. A systematic literature review catalogued pharmacists' activities with impact on patient outcomes. Primary endpoint: degree of correlation in three pair-wise comparisons between pharmacists' perceptions of impact, time allotted to activities, and published evidence of impact.

Results: Pharmacists' time spent was positively and significantly correlated with their perception of impact $(P=0.037)$ but not with the published evidence of impact (in either of the two analytical scenarios). The correlation between published evidence and pharmacists' perceptions of impacts was on the threshold of statistical significance with a moderate strength of association in one of the two analytical scenarios used.

Conclusions: Pharmacists dedicate more of their clinical time to activities they perceive to have greater impact. However, these perceptions and their time allocation does not correlate well with published evidence, and some misperceptions about impacts deserve correction. More rigorous research is needed to quantify the value of pharmacist services to the health care system,
\end{abstract}

\footnotetext{
"Peter LOEWEN. B.Sc.(Pharm), ACPR, Pharm.D., FCSHP. Associate Professor, Faculty of Pharmaceutcial Sciences, University of British Columbia, and Regional Pharmacy Coordinator - Education \& Research, $\mathrm{VCH}$ PHC Regional Pharmacy Services. Vancouver (Canada). Faye MERRETT. B.Sc.(Pharm), ACPR. Clinical pharmacist, Vancouver General Hospital. Vancouver (Canada).

Jane DE LEMOS. PharmD, MSc (Epid). Regional

Pharmacy Coordinator - Professional Practice, VCH-PHC Regional Pharmacy Services. Vancouver (Canada).
}

however designing such studies to isolate the value of specific activities will be challenging.

Keywords: Pharmacists. Professional Role. Canada.

\section{PERCEPCIONES DE LOS \\ FARMACÉUTICOS DE LOS CUIDADOS QUE ELLOS PROPORCIONAN}

\section{RESUMEN}

Las limitaciones en los recursos sanitarios obligan a centrarse claramente en las actividades que llevan a mayores mejorías en los resultados de los pacientes. A pesar de la importancia de alinear el tiempo de los farmacéuticos con las actividades que producen el mayor impacto, hay poca literatura sobre la correlación entre las percepciones de los farmacéuticos sobre el impacto de sus actividades y como emplean realmente su tiempo y como este se aliena con la evidencia publicada sobre el impacto en los resultados de los pacientes.

Objetivo: Revelar las percepciones de los farmacéuticos hospitalarios sobre el impacto de sus actividades clínicas y caracterizar la correlación entre las actividades realizadas y sus percepciones y la evidencia publicada sobre el impacto de sus cuidados.

Métodos: Se realizaron entrevistas observacionales cualitativas y cuestionarios cuantitativos con cada participante $(\mathrm{N}=21)$ para caracterizar su trabajo diario y determinar sus percepciones sobre el impacto de sus actividades. Una revisión sistemática catalogó las actividades de los farmacéuticos y su impacto sobre los resultados de los pacientes. Resultado primario: grado de correlación entre tres comparaciones emparejadas entre las percepciones de los farmacéuticos sobre el impacto, el tiempo destinado a las actividades y la evidencia publicada sobre ese impacto.

Resultados: El tiempo de los farmacéuticos estaba positiva y significativamente correlacionado con su percepción con su percepción del impacto $(\mathrm{P}=0,037)$, pero no con la evidencia publicada del impacto (en cualquiera de los dos escenarios de análisis). La correlación entre la evidencia publicada y las percepciones del impacto estaba en el umbral de la significación estadística con una fuerza moderada de asociación en uno de los dos escenarios utilizados.

Conclusiones: Los farmacéuticos dedican más tiempo clínico a las actividades que ellos perciben de mayor impacto. Sin embargo, estas percepciones y el tiempo dedicado no se correlacionan bien con la evidencia publicada y existe alguna mala 
interpretación sobre los impactos que merece corrección. Se necesita una investigación más rigurosa para cuantificar el valor de los servicios farmacéuticos sobre el sistema sanitario, sin embargo, será difícil diseñar esos estudios que aíslen el valor específico de las actividades.

Palabras clave: Farmacéuticos. Papel profesional. Canadá.

\section{INTRODUCTION}

Limitations on health care resources necessitate careful focus on activities that lead to the greatest improvement in patient outcomes.

Several studies have shown that hospital-based clinical pharmacist services improve patient outcomes via reducing length of stay (LOS), serious adverse advents, morbidity and mortality. ${ }^{1-4}$ Furthermore, studies have also shown that the incorporation of pharmacists into care teams can significantly reduce health care $\operatorname{costs}^{1,2,4-6}$ and because of their training in pharmacology and familiarity with medications, pharmacists perform certain activities with more accuracy in the clinical setting. ${ }^{7}$ Observational data exists documenting clinical pharmacists' activities ${ }^{8}$, however, pharmacists have their own perceptions about the impacts of the activities they perform, and these perceptions may influence how they spend their time providing direct patient care. Despite the importance of aligning pharmacists' time with activities deriving the most impact, there is a paucity of literature on the correlations between pharmacists' perceptions of the impacts of the activities that they perform, how they actually spend their time and how these align with published evidence for impacts on patient outcomes. In addition, pharmacists' own perceptions of what constitutes quality care in their practice area are a possible foundation for quality measurement.

The purpose of this study was to reveal hospital pharmacists' perceptions of the impacts of their clinical activities and to characterize the correlation between the activities performed and both their perceptions of and the published evidence for their impacts on patient care. Such data could help identify opportunities for realignment of pharmacists' activities to optimize patient outcomes.

\section{METHODS}

\section{Study Design and Organization}

This study consisted of observational qualitative interviews, quantitative questionnaires, and a systematic literature review. Ethical and administrative approval for the research was obtained.

\section{Study Population}

Study participants consisted of a convenience sample of clinical pharmacists employed by
Vancouver Coastal Heath and Providence Health Care Pharmacy Services, a multi-institution regionalized service delivery organization. Participants were selected by the investigators to be representative of multiple sites, practice settings and training levels.

Participants were enrolled over a five month period from November 2008 to March 2009. Pharmacists were eligible to participate if they had direct patient care responsibilities at least $50 \%$ of the time, had a minimum of 1 year of experience as a clinical pharmacist, and provided written consent.

\section{Pharmacist Activities}

A compendium of 35 discreet clinical pharmacist activities was developed by reviewing published literature, compiling the investigators' own experience and interviewing a pilot cohort of clinical pharmacists. The first questionnaire asked each study subject to estimate how much time they allocate to each activity on a daily basis, using seven time categories ranging from none to "more than 3 hours/day". The responses to the first questionnaire were elicited during individual meetings between each participant and one of the study investigators. In this meeting, demographic data (experience, main care areas, and training) was collected and a 30-40 minute recorded, semistructured, qualitative interview was also conducted.

Published Evidence of Impact on Patient Outcomes

A review of published literature for the period 1978 to April 2009 was conducted to identify discreet hospital pharmacist activities evaluated for evidence of impact on clinical outcomes. PubMed, Embase, International Pharmaceutical Abstracts, and Cochrane Database of Systematic Reviews were searched using the terms: pharmacist, clinical pharmacy, pharmaceutical care, pharmacy services, mortality, morbidity, adverse reaction, outcome and each previously-identified activity individually. Hand searches of bibliographies of relevant articles were performed. Studies presented in abstracts, letters to the editor, editorials, reviews, pediatric studies, and studies occurring in the primary care setting were excluded from this review. Methods of identified studies were reviewed for required criteria, including pharmacy service or intervention described, presence of a control group, and identification of patient-specific clinical outcomes as endpoints.

The patient-specific clinical outcomes were arranged into a hierarchy of impacts, from lowest to highest ( 0 to 7$)$ as follows: no benefit, improve patient satisfaction, improve quality of life, reduce adverse events, reduce morbidity, reduce LOS, decrease hospital readmissions, and decrease mortality. The investigators created this hierarchy based on consensus since no relevant validated or generally-accepted outcomes hierarchy including both clinical and humanistic outcomes exists. Where conflicting evidence existed in published literature the greatest impact identified was the impact score assigned. This optimistic assignment was chosen because most published studies were not powered to find a significant difference in clinical outcomes and blending studies for a particular 
activity was felt to give too much weight to such studies.

Pharmacist Perceptions of Impact on Patient Outcomes

Between two to eight weeks after the initial interview, the same pharmacists completed a second questionnaire which elicited their perceptions of the impact their clinical activities have on patient outcomes by identifying which patient outcomes from the above hierarchy are improved by each activity they perform. This questionnaire, sent electronically to each participant, was individualized in that it contained only the activities previously identified by them as being performed. Where more than one outcome could be impacted by an activity (for example, length of stay and hospital readmission could both be impacted by medication optimization), the highest-level impact was used for analysis. Time separation between the two questionnaires was designed to reduce potential bias associated with pharmacists reflecting on how much time they spend on activities and the impacts of those at the same time. The second questionnaire did not remind them of how much time they previously claimed to spend on activities, only the activities themselves.

Analysis

Data was extracted for analysis from the qualitative interviews, completed questionnaires, and literature review.

The primary endpoint for this study was the degree of correlation within the following three comparisons:

- Pharmacists' perceptions of impacts versus the amount of time spent on the activities performed [Comparison 1].

- Published evidence of impacts versus the amount of time spent on the activities performed [Comparison 2].

- Pharmacists' perceptions of impacts versus the best available published evidence of impacts [Comparisons 3].

Nonparametric descriptive statistics were used to represent the time spent per activity, the perceived impact of each activity, and the correlation coefficient (Spearman's rho), for each of the comparisons (using SPSS). Strength of association was described using Cohen's criterion. ${ }^{9}$

Because not all activities had published evidence for or against them, two policies were developed to represent different interpretations of the lack of evidence. Policy 1, a conservative approach, assumed if an activity had no evidence of impact on patient outcomes, that activity had no benefit. Policy 2, a liberal approach, omitted from the analysis activities without any evidence. These policies were applied to comparisons 2 and 3 where published evidence of impact of activities was one of the comparators.

\section{RESULTS}

Twenty one pharmacists $(\mathrm{N}=21)$ were interviewed and completed the questionnaires with $100 \%$ completion. This represented a broad spectrum of clinical pharmacists from different hospitals, areas of practice, and years of experience (Table 1).

\begin{tabular}{|l|r|}
\hline \multicolumn{2}{|c|}{ Table 1. Participant characteristics (N=21) } \\
\hline \multicolumn{2}{|c|}{ No. of } \\
participants \\
\hline Years of experience & 7 \\
$<5$ & 6 \\
$5-10$ & 8 \\
$>10$ & \\
\hline Highest level of training & 1 \\
B.Sc.(Pharm) & 16 \\
Residency & 4 \\
Pharm. D. & \\
Primary area of practice & 17 \\
Medicine & 4 \\
General medicine & 2 \\
Psychiatry & 2 \\
Cardiology & 2 \\
Leukemia/BMT & 2 \\
HIV & 1 \\
ICU & 1 \\
ER & 1 \\
Pediatrics & 1 \\
Nephrology & 1 \\
Palliative Care & 4 \\
Surgery & 2 \\
General surgery & 1 \\
Vascular surgery & 1 \\
Burns/plastics/trauma & 18 \\
\hline Care setting & 3 \\
Inpatient & \\
Outpatient & \\
\hline
\end{tabular}

Thirty five clinical pharmacist activities were assessed in the first questionnaire by the participants to determine pharmacists' time allocation to those activities (Table 2).

Participants often stated they found it difficult to assign an average time to each activity, as their daily routine varies significantly, for example, more preparation time is needed earlier in the week, patient discharges requiring counselling varies, rounds may not be every day, and an occasional Special Access drug application can consume a few hours.

Pharmacists later assessed each activity they performed in terms of their perceived impact on patient outcomes (Table 2). Activities which participants perceived to have the greatest impact were attending patient care rounds, monitoring drug therapy, initiating drug therapy, antibiotic optimization, and clinical research. Activities believed to impart no benefit on patient outcomes were organization of day, teaching pharmacy students and residents, and providing in-services to other health care professionals.

\section{Published Evidence of Impact}

Of 595 publications identified, 47 met the inclusion criteria. A systematic review conducted by Kaboli has previously reviewed 28 of these publications. ${ }^{10}$ This literature review found 21 of the 35 activities to have positive impact on patient outcomes (Table 2 ). 
Table 2. Results of the two questionnaires and systematic literature review.

\begin{tabular}{|c|c|c|c|}
\hline Activity & $\begin{array}{l}\text { Median time } \\
\text { (min/day) per } \\
\text { activity }\end{array}$ & $\begin{array}{l}\text { Median perceived impact } \\
(\text { ranked score - see Table } 3)^{*}\end{array}$ & $\begin{array}{l}\text { Published impact } \\
\text { (score assigned - see Table 3) }\end{array}$ \\
\hline Organization of day & $20-39$ & No benefit (0) & $\mathrm{N} / \mathrm{A}$ \\
\hline Review laboratory/microbiology & $20-39$ & $\downarrow \operatorname{LOS}(5)$ & $\downarrow$ adverse events ${ }^{15}(3)$ \\
\hline $\begin{array}{l}\text { Review } \\
\text { profiles }\end{array}$ & $40-59$ & $\downarrow$ hospital readmissions $(6)$ & $\downarrow$ adverse events ${ }^{15}(3)$ \\
\hline Chart review & $60-119$ & $\downarrow$ hospital readmissions $(6)$ & $\downarrow$ adverse events ${ }^{15}(3)$ \\
\hline Attend patient care rounds & $40-59$ & $\downarrow$ mortality $(7)$ & $\downarrow$ mortality ${ }^{11}(7)$ \\
\hline Medication history & $20-39$ & $\downarrow$ morbidity /LOS (4.5) & $\downarrow$ mortality $^{3,5,11}(7)$ \\
\hline Medication reconciliation at admission & $20-39$ & $\downarrow \operatorname{LOS}(5)$ & $\mathrm{N} / \mathrm{A}$ \\
\hline Medication reconciliation at transfer & $1-20$ & $\downarrow$ adverse events (3) & $\downarrow$ adverse events ${ }^{16}(3)$ \\
\hline Medication reconciliation at discharge & $20-39$ & $\downarrow$ hospital readmissions $(6)$ & $\downarrow$ hospital readmissions ${ }^{10}(6)$ \\
\hline Assess allergies & $1-20$ & $\downarrow \operatorname{LOS}(5)$ & $\mathrm{N} / \mathrm{A}$ \\
\hline Medication counselling & 20-39 & $\downarrow$ hospital readmissions $(6)$ & $\downarrow$ hospital readmissions ${ }^{17}(6)$ \\
\hline Discharge counselling & $20-39$ & $\downarrow$ hospital readmissions $(6)$ & $\downarrow$ hospital readmissions ${ }^{10,18}(6)$ \\
\hline Continuity of care & $1-20$ & $\downarrow$ hospital readmissions $(6)$ & $\downarrow$ mortality $^{14}(7)$ \\
\hline Call patient's family physician & $1-20$ & $\downarrow$ hospital readmissions $(6)$ & N/A \\
\hline Call patient's pharmacy & $1-20$ & $\downarrow$ hospital readmissions $(6)$ & $\mathrm{N} / \mathrm{A}$ \\
\hline Drug therapy monitoring & $40-59$ & $\downarrow$ mortality $(7)$ & $\downarrow$ hospital readmissions ${ }^{19,20}(6)$ \\
\hline Dosage adjustments & $20-39$ & $\downarrow \operatorname{LOS}(5)$ & $\mathrm{N} / \mathrm{A}$ \\
\hline Initiate medications & 20-39 & $\downarrow$ mortality (7) & $\mathrm{N} / \mathrm{A}$ \\
\hline Discontinue medications & $20-39$ & $\downarrow \operatorname{LOS}(5)$ & $\mathrm{N} / \mathrm{A}$ \\
\hline Monitor for side effects & $40-59$ & $\downarrow$ hospital readmissions $(6)$ & $\downarrow$ mortality ${ }^{11,12}(7)$ \\
\hline Monitor for drug interactions & $20-39$ & $\downarrow$ hospital readmissions $(6)$ & $\mathrm{N} / \mathrm{A}$ \\
\hline Antibiotic optimization & $20-39$ & $\downarrow$ mortality $(7)$ & $\downarrow$ mortality ${ }^{10}(7)$ \\
\hline IV to PO conversion & $1-20$ & $\downarrow \operatorname{LOS}(5)$ & $\downarrow \operatorname{LOS}^{21}(5)$ \\
\hline TDM & $20-39$ & $\downarrow$ hospital readmissions $(6)$ & $\downarrow$ hospital readmissions ${ }^{10}(6)$ \\
\hline Warfarin dosing & $20-39$ & $\downarrow \operatorname{LOS}(5)$ & $\downarrow$ mortality $^{13}(7)$ \\
\hline VTE prophylaxis & $20-39$ & $\downarrow$ hospital readmissions $(6)$ & $\downarrow$ mortality ${ }^{13}(7)$ \\
\hline Manage non-formulary meds & $1-20$ & $\uparrow$ patient satisfaction (1) & $\mathrm{N} / \mathrm{A}$ \\
\hline Documentation on own form & $20-39$ & $\downarrow$ adverse events (3) & $\mathrm{N} / \mathrm{A}$ \\
\hline Documentation in patient's chart & $20-39$ & $\downarrow \operatorname{LOS}(5)$ & $\mathrm{N} / \mathrm{A}$ \\
\hline $\begin{array}{l}\text { Teaching pharmacy students/ residents } \\
\text { and Pharm D's }\end{array}$ & $20-39$ & No benefit $(0)$ & $\mathrm{N} / \mathrm{A}$ \\
\hline Inservice provision & $1-20$ & No benefit $(0)$ & $\downarrow$ mortality ${ }^{11}(7)$ \\
\hline Literature evaluation & $1-20$ & $\downarrow$ adverse events (3) & $\mathrm{N} / \mathrm{A}$ \\
\hline Clinical research & $1-20$ & $\downarrow$ mortality $(7)$ & $\downarrow$ mortality $^{3}(7)$ \\
\hline $\begin{array}{l}\begin{array}{l}\text { Responding to } \\
\text { questions }\end{array} \\
\text { que information } \\
\end{array}$ & $10-30$ & $\downarrow \operatorname{LOS}(5)$ & $\downarrow$ mortality $^{3}(7)$ \\
\hline Management of drug protocols & $1-20$ & $\downarrow \operatorname{LOS}(5)$ & $\downarrow$ mortality ${ }^{11}(7)$ \\
\hline
\end{tabular}

Activities with the greatest impact on patient outcomes, i.e., associated with mortality reduction, included: attending patient care rounds ${ }^{11}$, taking medication histories at admission ${ }^{3,5,11}$, monitoring for side effects ${ }^{11,12}$, optimizing antibiotics $^{11}$, providing warfarin dosing services ${ }^{13}$, monitoring venous thromboembolism (VTE) prophylaxis ${ }^{13}$, providing in-services ${ }^{11}$, conducting clinical research $^{3}$, responding to drug information questions $^{3}$, providing continuity of care $^{14}$, and managing drug protocols. ${ }^{11}$ Examples of activities without any identified evidence on patient outcomes included assessing patients' allergies, monitoring for side effects or drug interactions, calling a family physician, organization of day, and making dosage adjustments.

\section{Comparison 1}

Pharmacists' time spent was statistically significantly $(P=0.037)$ and positively correlated with 
their perceptions of impact (Figure 1). This association had moderate strength (Spearman rho=0.354) per Cohen's criteria.

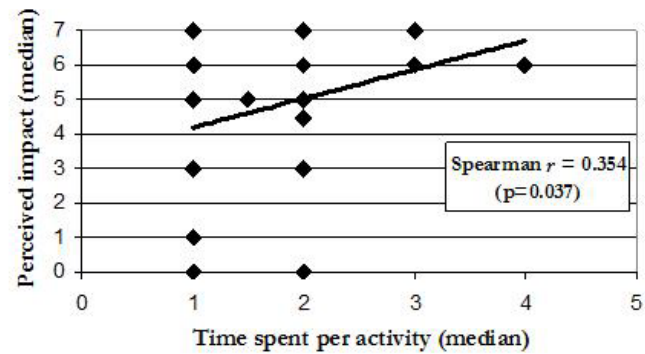

Figure 1. Comparison 1 of in-depth questionnaires: median time spent per activity versus median perceived impact of activity $(\mathrm{N}=35)$. Refer to Table 3 for translation of axis values.

\begin{tabular}{|c|c|}
\hline \multicolumn{2}{|c|}{ Time per activity } \\
\hline 0 & Not performed \\
\hline 1 & $1-20 \mathrm{~min} /$ day \\
\hline 2 & 20-39 min/day \\
\hline 3 & $40-59 \mathrm{~min} /$ day \\
\hline 4 & $60-119 \mathrm{~min} /$ day \\
\hline 5 & $120-180 \mathrm{~min} / \mathrm{day}$ \\
\hline 6 & $>180 \mathrm{~min} /$ day \\
\hline \multicolumn{2}{|l|}{ Impact } \\
\hline 0 & No benefit \\
\hline 1 & 个 patient satisfaction \\
\hline 2 & $\uparrow$ quality of life \\
\hline 3 & $\downarrow$ adverse events \\
\hline 4 & $\downarrow$ morbidity \\
\hline 5 & $\downarrow$ LOS \\
\hline 6 & $\downarrow$ hospital readmissions \\
\hline 7 & $\downarrow$ mortality \\
\hline
\end{tabular}

\section{Comparison 2}

Pharmacists' time spent was not statistically significantly correlated with published evidence of impact (figure 2), in both policy 1 (conservative) and policy 2 (liberal) scenarios $(p=0.665$ and 0.523 , respectively). Even if these correlation coefficients (Spearman rho $=0.076$ and -0.148 , respectively) were statistically significant, they would indicate a weak association based on Cohen's criteria. Hence, there is not a clear association between time spent on activities and published evidence of impact of those activities.

\section{Comparison 3}

Overall, pharmacists' perceptions of impacts were not statistically significantly correlated with published evidence of impacts under policy 1 (conservative) $(p=0.054)$, however this result was on the threshold of statistical significance and the strength of association was "moderate" (Spearman rho=0.328). When a liberal measurement policy was used (policy 2), the association was not statistically significant $(p=0.709)$, and the association was weak (Spearman rho=0.087).
Pharmacists' perceived impact and published impact were concordant (overlap of perceived impact and published impact) in 21 of the 35 activities and discordant (error bars of perceived impact do not overlap with published impact) for the other 14 (Figure 3) if assuming no impact where evidence of impact is non-existent. Of the 21 activities with evidence of impact, 16 were concordant and 5 were discordant. Of the discordant activities, pharmacists perceptions exceeded published impact for 2 activities (PharmaNet/medication profile review and laboratory/microbiology review) and undervalued 3 activities compared to published literature (taking medication history, providing in-services, and answering drug information questions). We did not encounter conflicting data in relation to these activities.

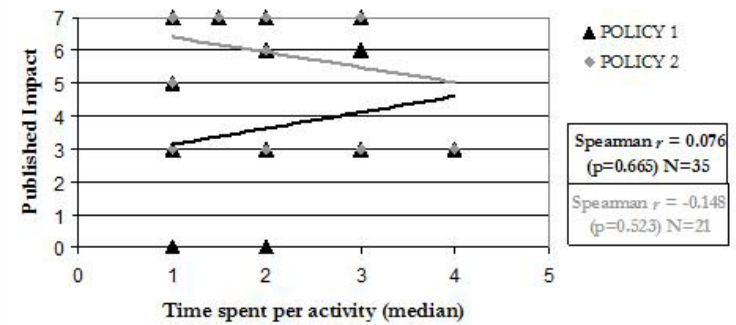

Figure 2. Comparison 2: median ranked time spent per activity versus published impact of activity, measuring with a conservative (Policy 1 ) and a liberal (Policy 2) approach. Refer to Table 3 for translation of axis values.

\section{DISCUSSION}

Based on this intensive evaluation of a relatively small cohort of hospital-based pharmacists, we found that there is an association between how pharmacists spend their time and their perceptions of the clinical impacts of those activities. It is less clear, however, that how they spend their time aligns well with published evidence of clinical impact. Similarly, our data do not convincingly show that pharmacists' perceptions of impact align well with published evidence of impacts, although our results were on the verge of statistical significance for a weak/moderate association here and pharmacists perceptions of impact were concordant with published evidence for the majority of activities performed.

The first finding lends validity to our methodologic approach, since it is expected that pharmacists will spend their time doing activities they believe to be most impactful. This finding also raises the hypothesis that interventions aimed at changing pharmacists perceptions of impact (e.g., education) could cause them to change how they spend their time.

The latter two findings have several implications. First, it may be important for pharmacists and their managers to better familiarize themselves with the published literature for activities which have impact and those which do not or for which there is no evidence available. Second, we did identify some 


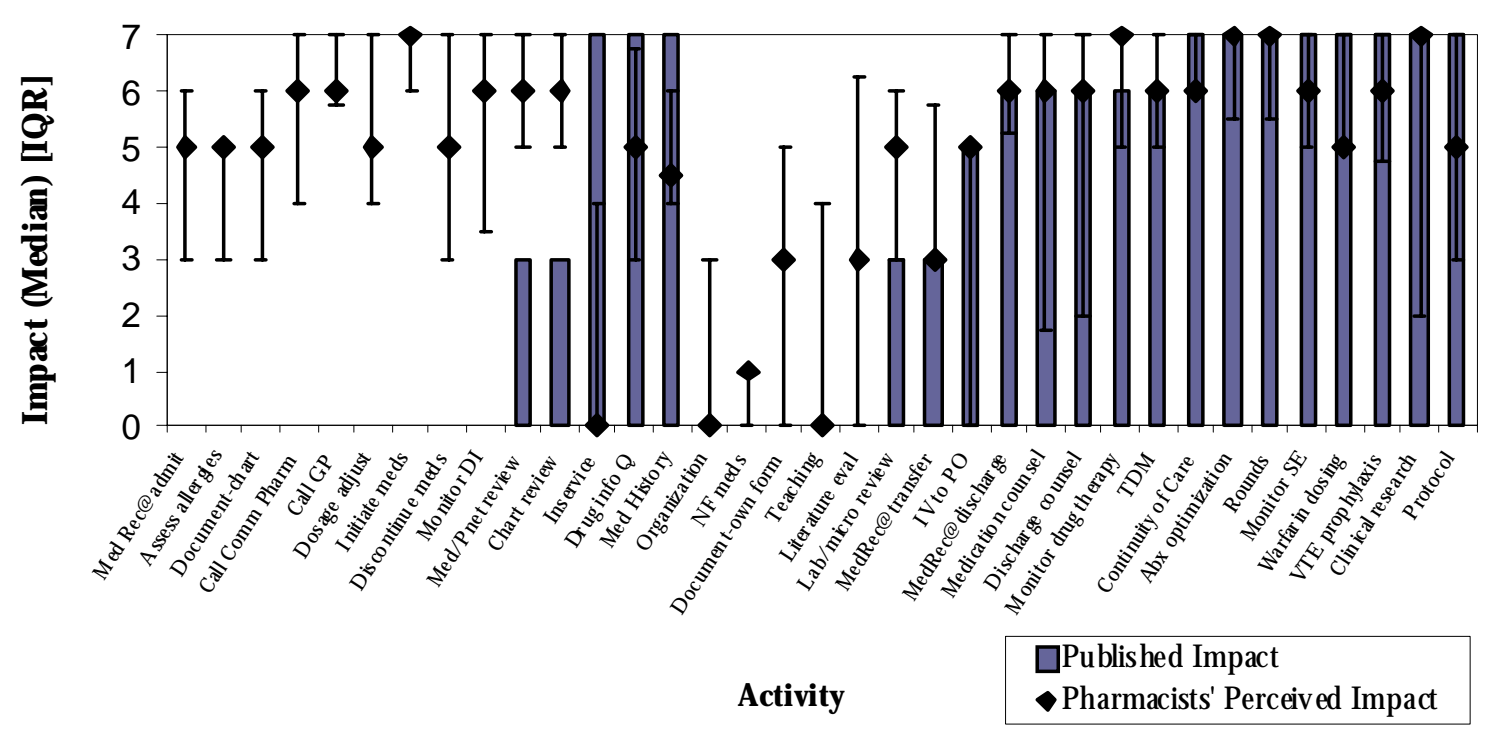

Figure 3. Comparison 3: published impact and pharmacists' median perceived impact (with 1st and 3rd quartile ranges as error bars) for each activity. Refer to Table 3 for translation of $y$-axis values.

specific activities which pharmacists had misperceptions about - taking medication history, providing in-services, and answering drug information questions - whereby realignment of their time away from other activities less justified by the published literature toward these activities could enhance their clinical impact. We suggest our findings of discordance could be very important as they represent opportunities to realign pharmacists' time and effort with activities of greater impact. Doing this would shift pharmacists from not just delivering evidenced-based therapeutics for patients but organizing ourselves to practice in an evidenced-based way by ensuring we perform those activities associated with the greatest impact. Finally, our results highlight the need for more systematic investigation into the impacts of activities performed by pharmacists, and raise questions of how pharmacists should spend their time in the absence of such evidence.

This study had limitations which should be considered. The convenience sampling may have introduced selection bias by enrolling only pharmacists willing to discuss their job and perceptions. Not all clinical areas were included, (e.g. there were no residential care, respirology, or TPN pharmacists). The hierarchy of outcomes generated for this study is subjective, but we believe, clinically sensible. In addition, when tabulating the findings of published literature, we assigned the highest impact reported, not necessarily from the most rigorously performed study. Although we believe this was the best available strategy, it exposed our results to the weaknesses in the literature.

Discreet pharmacist activities, in general, are difficult to study. Most studies have evaluated specific services pre- and post-implementation, such as the effect of an infectious disease pharmacist, rather than well defined discrete activities. In addition, the heterogeneity of the published study designs makes it impossible to conduct a meta-analysis of the data. ${ }^{10}$ Some discrete activities are prerequisite steps to perform a function such as calling a family doctor (not studied) to provide continuity of care (studied), or reviewing microbiology data (shown to reduce adverse events) to optimize antibiotic therapy (shown to reduce mortality). Certain results in this study appear conflicting and may be in part due to the way we grouped discrete activities or the lack of definition or purpose of the activity. Specifically, grouping PharmaNet review with Medication profile review (perceived to reduce hospital readmissions, an overestimate) may have been misleading because this composite activity may be interpreted by some pharmacists as a required step in performing a medication history (perceived to reduce morbidity and LOS, an underestimate) and subsequent medication reconciliation (perceived to reduce LOS, not studied). Furthermore, many of the activities reported in this paper with mortality reduction were drawn from Bond's publications ${ }^{2-5,11-}$ 13 , which is survey-based data, thus not as strong as data derived from a randomized controlled trial. Finally, it is possible that the population studied here is atypical of pharmacists in other jurisdictions or that the sample size is too small to make robust conclusions of pharmacists' perceptions outside our jurisdiction.

Given the inherent difficulty of studying the value of discrete activities, the importance of absence of evidence of impact of some activities may be questioned if an activity seems important to be performed regardless of evidence of benefit. Nevertheless, our key finding is that there is discordance between pharmacists' perceived impact and published evidence of impact - specific activities were perceived to be of low impact (and thus presumably less time is spent on these) when actually there is published evidence of benefit. Similarly, pharmacists spend time on activities of 
unknown impact. We suggest that this discordance be minimized in the interests of maximizing pharmacist' impact and efficiency

\section{CONCLUSIONS}

Hospital-based pharmacists provide a wide variety of services and they believe those services to be of value in improving patient outcomes. Pharmacists dedicate more of their clinical time to activities they perceive to have greater impact. However, these perceptions and how they spend their time do not correlate well with published evidence of patient impact, and a few misperceptions about impacts deserve correction. More rigorous research is needed to quantify the value of pharmacist services to the health care system, however designing such studies to isolate the value of specific activities will be challenging.

\section{CONFLICT OF INTEREST}

None of the authors have conflicts of interest related to this work. This study was unfunded.

\section{References}

1. Bjornson DC, Hiner WO Jr, Potyk RP, Nelson BA, Lombardo FA, Morton TA, Larson LV, Martin BP, Sikora RG, Cammarata FA. Effect of pharmacists on health care outcomes in hospitalized patients. Am J Hosp Pharm. 1993;50(9):1875-84.

2. Bond CA, Raehl CL. Clinical and economic outcomes of pharmacist-managed antimicrobial prophylaxis in surgical patients. Am J Health Syst Pharm. 2007;64(18):1935-42.

3. Bond CA, Raehl CL, Franke T. Clinical pharmacy services and hospital mortality rates. Pharmacotherapy. 1999;19(5):556-64

4. Bond CA, Raehl CL, Franke T. Clinical pharmacy services, pharmacist staffing, and drug costs in united states hospitals. Pharmacotherapy. 1999;19(12):1354-62.

5. Bond CA, Raehl CL, Franke T. Interrelationships among mortality rates, drug costs, total cost of care, and length of stay in united states hospitals: Summary and recommendations for clinical pharmacy services and staffing. Pharmacotherapy. 2001;21(2):129-41.

6. Torchinsky A, Landry D. An analysis of pharmacist interventions. Can J Hosp Pharmacy. 1991;44(5):245,-248,270.

7. Crook M, Ajdukovic M, Angley C, Soulsby B, Doecke C, Stupans I, Angley M. Eliciting comprehensive medication histories in the emergency department: the role of the pharmacist. Pharm Pract (Internet) 2007;5(2):78-84.

8. Stuchbery P, Kong DCM, Desantis GN, Lo SK. Identification by observation of clinical pharmacists' activities in a hospital inpatient setting. Pharm Pract (Internet) 2007;5(1):10-16.

9. Cohen, J. Statistical power analysis for the behavioral sciences. Hillsdale (NJ): Erlbaum; 1988.

10. Kaboli PJ, Hoth AB, McClimon BJ, Schnipper JL. Clinical pharmacists and inpatient medical care: A systematic review. Arch Intern Med. 2006;166(9):955-64.

11. Bond CA, Raehl CL. Clinical pharmacy services, pharmacy staffing, and hospital mortality rates. Pharmacotherapy. 2007;27(4):481-93.

12. Bond CA, Raehl CL. Clinical pharmacy services, pharmacy staffing, and adverse drug reactions in united states hospitals. Pharmacotherapy. 2006;26(6):735-47.

13. Bond CA, Raehl CL. Pharmacist-provided anticoagulation management in united states hospitals: Death rates, length of stay, medicare charges, bleeding complications, and transfusions. Pharmacotherapy. 2004;24(8):953-63.

14. Wu JY, Leung WY, Chang S, Lee B, Zee B, Tong PC, Chan JC. Effectiveness of telephone counselling by a pharmacist in reducing mortality in patients receiving polypharmacy: Randomised controlled trial. BMJ. 2006;333(7567):522.

15. Zermansky AG, Alldred DP, Petty DR, Raynor DK, Freemantle N, Eastaugh J, Bowie P. Clinical medication review by a pharmacist of elderly people living in care homes--randomised controlled trial. Age Ageing. 2006;35(6):586-91.

16. Boockvar KS, Carlson LaCorte H, Giambanco V, Fridman B, Siu A. Medication reconciliation for reducing drugdiscrepancy adverse events. Am J Geriatr Pharmacother. 2006;4(3):236-43.

17. Stiegler KA, Yunker NS, Crouch MA. Effect of pharmacist counseling in patients hospitalized with acute exacerbation of asthma. Am J Health Syst Pharm. 2003;60(5):473-6.

18. López Cabezas C, Falces Salvador C, Cubí Quadrada D, Arnau Bartés A, Ylla Boré M, Muro Perea N, Homs Peipoch E. Randomized clinical trial of a postdischarge pharmaceutical care program vs regular follow-up in patients with heart failure. Farm Hosp. 2006;30(6):328-42.

19. Gattis WA, Hasselblad V, Whellan DJ, O'Connor CM. Reduction in heart failure events by the addition of a clinical pharmacist to the heart failure management team: Results of the pharmacist in heart failure assessment recommendation and monitoring (PHARM) study. Arch Intern Med. 1999;159(16):1939-45.

20. Bond CA, Salinger RJ. Fluphenazine outpatient clinics: A pharmacist's role. J Clin Psychiatry. 1979;40(12):501-3.

21. Kuti JL, Le TN, Nightingale CH, Nicolau DP, Quintiliani R. Pharmacoeconomics of a pharmacist-managed program for automatically converting levofloxacin route from i.v. to oral. Am J Health Syst Pharm. 2002;59(22):2209-15. 